\title{
A STUDY OF C-REACTIVE PROTEIN LEVELS IN ACUTE CORONARY SYNDROME AND A CORRELATION WITH THE OUTCOME
}

\author{
Umamaheshwari S1, Vishwanatha Huggi', Mahesh Menon ${ }^{3}$, Arunkumar ${ }^{4}$, Sireesh Kumar ${ }^{5}$ \\ ${ }_{1}^{1}$ Assistant Professor, Department of General Medicine, VIMS, Bellary. \\ ${ }^{2}$ Assistant Professor, Department of General Medicine, VIMS, Bellary. \\ ${ }^{3}$ Postgraduate Student, Department of General Medicine, VIMS, Bellary. \\ ${ }_{4}^{4}$ Postgraduate Student, Department of General Medicine, VIMS, Bellary. \\ 5 Postgraduate Student, Department of General Medicine, VIMS, Bellary.
}

\section{ABSTRACT}

\section{BACKGROUND}

Coronary artery disease has emerged as the major cardiovascular disease of the era and also the commonest cause of premature death. Developing countries like India are expected to experience the greatest rise in cardiovascular disease burden over the next few years. In large part, this increase can be explained on the basis of major ongoing socio-demographic changes in developing countries and associated effects on the number of individuals at risk and the levels of cardiovascular risk factors. Atherosclerosis of the coronary vessels commonly causes ischaemic heart diseases. Recently, attention has been focused on the potential role of plasma markers of inflammation, especially C-Reactive Protein (CRP), as risk predictors among those at risk for cardiovascular events. Circulating levels of CRP were found to correlate with total infarct size in acute myocardial infarction and with prognosis. This study was conducted to identify the role of C-reactive protein in correlating the outcome in acute coronary syndrome.

\section{MATERIALS AND METHODS}

This is a case series study done in ICCU of VIMS, Bellary for a period of one year; 100 patients who came with history of typical angina chest pain and those who fit into the criteria for Acute Coronary syndrome with ECG showing either ST segment elevation or non-ST segment elevation myocardial infarction or unstable angina were included in the study. Detailed history, clinical examination and laboratory tests were the tools used to exclude these conditions. Apart from routine blood investigations, electrocardiography and transthoracic echocardiography was done in all patients. All patients were followed up and observed for the development of complications.

\section{RESULTS}

Out of the 100 patients studied, 44 patients had detectable C-reactive protein levels (equal to or more than $0.6 \mathrm{mg} / \mathrm{dL}$ ). Out of these 34 patients had complications (including death), which was found to be statistically significant, thus correlating the CRP levels with complications.

\section{CONCLUSION}

Our study highlights a possible correlation between CRP levels and adverse outcome in acute coronary syndrome. Plasma CRP levels on admission serves to identify high risk patients in the setting of acute coronary syndromes and are also independent markers of adverse outcomes. The effective risk stratification provided may be of specific value for early therapeutic decision making and patient treatment in the heterogeneous population of patients presenting with acute coronary syndromes.

\section{KEYWORDS}

Acute Coronary Syndrome, C-Reactive Protein, STEMI, Thrombolysis.

HOW TO CITE THIS ARTICLE: Umamaheshwari S, Huggi V, Menon M, et al. A study of C-reactive protein levels in acute coronary syndrome and a correlation with the outcome. J. Evolution Med. Dent. Sci. 2017;6(18):1417-1420, DOI: $10.14260 /$ Jemds/2017/310

\section{BACKGROUND}

Coronary artery disease has emerged as the major cardiovascular disease of the era and also the commonest cause of premature death. Developing countries now experience a much greater burden of cardiovascular disease than developed countries. In addition, developing countries

Financial or Other, Competing Interest: None.

Submission 09-02-2017, Peer Review 20-02-2017,

Acceptance 23-02-2017, Published 02-03-2017.

Corresponding Author:

Dr. Arunkumar,

Postgraduate Student,

Department of General Medicine,

VIMS, Bellary.

E-mail: drarunmahamani@gmail.com

DOI: $10.14260 /$ jemds $/ 2017 / 310$ like India are expected to experience the greatest rise in cardiovascular disease burden over the next few years. In large part, this increase can be explained on the basis of major ongoing socio-demographic changes in developing countries and associated effects on the number of individuals at risk and the levels of cardiovascular risk factors.

Despite progress in the prevention of cardiovascular diseases, a significant proportion of first cardiovascular events occur among individuals without traditional risk factors. Cardiovascular events develop unpredictably in patients with widely varying degrees of atherosclerotic diseases. Thus, major area of interest is the study of stimuli that provoke ischaemic events and merits continued attention from basic and clinical researchers, epidemiologists and practicing physicians. 
Atherosclerosis of the coronary vessels commonly causes ischaemic heart diseases.

The past decade has witnessed an increasing recognition that inflammatory mechanisms play a central role in the pathogenesis of atherosclerosis and its complications. Recently, attention has been focused on the potential role of plasma markers of inflammation, especially C-Reactive Protein (CRP) as risk predictors among those at risk for cardiovascular events. With inflammation, there will be release of inflammatory cytokines from the inflamed tissue, which stimulates liver to synthesise a number of acute phase proteins including the prototypical acute phase reactant, Creactive protein. Circulating levels of CRP were found to correlate with total infarct size in acute myocardial infarction and with prognosis.

\section{Aims and Objectives}

To study the clinical profile of patients with acute coronary syndrome and to study the correlation of CRP levels in acute coronary syndrome and their clinical outcome.

\section{MATERIALS AND METHODS}

This is a case series study done in ICCU of VIMS, Ballari for a period of one year; 100 patients who came with history of typical angina chest pain and those who fit into the criteria for Acute Coronary syndrome with ECG showing either ST segment elevation or non-ST segment elevation myocardial infarction or unstable angina were included in the study.

Patients with stable angina, non-cardiac causes of chest pain, recent history of major trauma or surgery, on immunosuppressants, immunological diseases and chronic arthritis were excluded from study. Also, those patients who were already on statins, aspirin, oral contraceptives, niacin or fibrates were excluded from the study and so were the patients diagnosed with any organ/systemic malignancies.

Detailed history, clinical examination and laboratory tests were the tools used to exclude these conditions. Apart from routine blood investigations, electrocardiography and transthoracic echocardiography was done in all patients. All patients were followed up and observed for the development of complications.

\section{Procedure for Performing C-Reactive Protein Assay}

The C-reactive protein assay was performed as a rapid slide agglutination test for the direct detection (Qualitative test) and semi-quantification for C-reactive protein was also done. The reagent used was a latex particle suspension coated with specific antihuman C-reactive protein antibodies, which agglutinates in the presence of CRP in serum of the patients. According to qualitative method of assay of C-reactive proteins estimation, a level equal to or more than $0.6 \mathrm{mg} / \mathrm{dL}$ is detected as positive. A level below $0.6 \mathrm{mg} / \mathrm{dL}$ is denoted as negative.

\section{Statistical Analysis}

Data related to all the study variables was entered into an excel sheet and after data filtration the data sheet was transferred and analysed using SPSS Software version 20.0. Appropriate descriptive statistics like percentages, mean and standard deviation was used to describe the data variables. Appropriate tests of significance like chi square tests were applied to study the correlation of CRP levels and the clinical outcome and a p value less than 0.01 was considered statistically significant.

\section{RESULTS}

Of the 100 patients, highest incidence of acute coronary syndrome was observed in the age group of $40-49$ years, accounting for $29 \%$ of patients. The youngest patient was 25 year old male who suffered an AWMI and the oldest was 78 years old male who also had an AWMI. Also it was observed that $75 \%$ were males and $25 \%$ were female patients. Out of 79 STEMI patients, 64 were males and 15 were females and out of 21 UA/NSTEMI patients there were 12 males and 9 females. Mean age of incidence in males was 52.2 years and that for females was 64.2 years.

The most common presenting complaint was chest pain in $83 \%$ patients followed by sweating in $72 \%$, breathlessness in $38 \%$, vomiting in $11 \%$, epigastric discomfort in $6 \%$ patients. Two patients presented atypically with diarrhoea.

The most common risk factor in this study was smoking accounting for $64 \%$ followed by dyslipidaemia, hypertension and diabetes. Out of 75 male patients 64 were smokers, 32 patients had history of hypertension, 22 were diabetics and 50 patients had lipid abnormalities. High triglycerides with low HDL cholesterol was seen in $24 \%$, while $16 \%$ had high LDL levels, while $10 \%$ patients had raised total cholesterol.

Out of the 100 patients studied 78 had STEMI, 16 had UA and 6 had NSTEMI. Out of the 78 patients of STEMI, the distribution was as follows - the most common type was extensive anterior wall MI (44 patients) followed by Inferior wall MI (18), Anteroseptal wall MI (7) and Anterolateral wall MI (4); 2 patients had Anterior wall with Inferior wall MI, 2 patients had Inferior wall MI with Right ventricular extension and 1 patient had Inferior wall MI with Posterior wall MI.

\begin{tabular}{|c|c|}
\hline Types of STEMI & No. of Patients \\
\hline Anterior wall MI - Extensive Anterior wall & 44 \\
Anteroseptal & 7 \\
Anterolateral & 4 \\
\hline Inferior wall MI - Inferior wall & 18 \\
- Inferior wall + Right & 2 \\
ventricular extension & 1 \\
- Inferior wall + Posterior wall & 2 \\
\hline Inferior wall + Anterior wall \\
\hline \multicolumn{2}{|c|}{ Table 1. Types of STEMI } \\
\hline
\end{tabular}

STEMI - ST Elevation Myocardial Infarction.

In our hospital, pharmacological reperfusion was performed on eligible candidates with streptokinase of 1.5 million units. Out of 78 STEMI patients, 69 patients underwent streptokinase thrombolysis. Chest pain more than 12 hours' duration and formed Q-waves (in 9 patients) was the commonest cause to withhold thrombolysis. Left ventricular failure was the most common complication in 10 patients followed by cardiogenic shock in 8 patients. Out of the 37 patients who developed complications, 8 patients died.

\begin{tabular}{|c|c|}
\hline Complications & $\begin{array}{c}\text { Percentage of } \\
\text { Patients }\end{array}$ \\
\hline Left ventricular failure & 10 \\
\hline Cardiogenic shock & 8 \\
\hline Conduction block - Complete heart block & 4 \\
- Left bundle branch block & 1 \\
- Atrioventricular block & 1 \\
\hline Tachyarrhythmias - Supraventricular & 1 \\
tachycardia & \\
- Ventricular tachycardia & 5 \\
\hline
\end{tabular}




\begin{tabular}{|c|c|}
\hline Recurrent angina & 1 \\
\hline Post-infarct angina & 4 \\
\hline Congestive cardiac failure & 2 \\
\hline Accelerated hypertension & 1 \\
\hline Table 2. Complications in Acute Coronary Syndrome \\
\hline
\end{tabular}

LVF - Left Ventricular Failure, CS - Cardiogenic Shock, CB Conduction Block, VT - Ventricular Tachycardia, SVT Supraventricular Tachycardia, RA - Recurrent Angina, PIA Post-Infarct Angina, CCF - Congestive Cardiac Failure, Acc. HTN - Accelerated Hypertension.

\section{C-Reactive Protein Levels at Admission}

In our study, 44 patients had C-reactive protein levels detectable (i.e. equal to or more than $0.5 \mathrm{mg} / \mathrm{dL}$ ).

\begin{tabular}{|c|c|c|c|}
\hline $\begin{array}{c}\text { C-Reactive } \\
\text { Protein } \\
\text { Levels }\end{array}$ & $\begin{array}{c}\text { Acute Coronary } \\
\text { Syndrome with } \\
\text { Complications }\end{array}$ & $\begin{array}{c}\text { Acute Coronary } \\
\text { Syndrome } \\
\text { without } \\
\text { Complications }\end{array}$ & Total \\
\hline$<0.6 \mathrm{mg} / \mathrm{dL}$ & 3 & 53 & 56 \\
\hline$>0.6 \mathrm{mg} / \mathrm{dL}$ & 34 & 10 & 44 \\
\hline Total & $\mathbf{3 7}$ (p < 0.01) & $\mathbf{6 3}$ (p < 001) & $\mathbf{1 0 0}$ \\
\hline \multicolumn{2}{|r|}{ Table 3. CRP Levels in Patients with ACS } \\
\hline
\end{tabular}

Chi Square value found out by Yates correction, $\mathrm{X}^{2} \mathrm{yc}=$. At one degree of freedom, $p$ value is highly significant ( $p<0.01)$. This indicates that the patients with high serum C-Reactive Level at admission are prone for going into complications and levels were low in patients who did not undergo complications.

The table indicates that the patients with high serum CReactive Level at admission are prone for going into complications.

\section{Other Investigations}

In this study, ESR was raised in $62 \%$ of patients which included 42 males and 20 females. Leukocytosis is seen in the setting of acute coronary syndrome, but we observed raised leukocyte counts only in $24 \%$ of patients. Raised blood glucose levels were found in $22 \%$ of patients, out of which 20 were known diabetes mellitus patients. Diabetes mellitus is one of the risk factor for ischaemic heart disease and is considered as ischaemic heart disease equivalent.

\section{DISCUSSION}

In our study, mean age of occurrence of ACS was 59.2 years. When compared to the studies by Foussas et $\mathrm{al}^{1}$ and Mohmoud Suleiman et $\mathrm{al}^{2}$ where the mean age was in the seventh decade, ours were one decade earlier. Other studies done in Indian subcontinent also showed that coronary artery diseases occur a decade earlier than the Western population; $75 \%$ of our patients were males and $25 \%$ females. This is comparable to the Foussas et al (79\% males) and Mohmoud Suleiman et al (80\% males) study. Chest pain was the most common presenting symptom present in $83 \%$ of patients. It is comparable to study by Huggins et al done in 1996.3

In our study history of chronic smoking was the most common risk factor found in $64 \%$ patients. In Foussas et al ${ }^{1}$ study smoking was observed in $57 \%$ of patients, while in Mohmoud Suleiman et al $^{2}$ study smoking was observed in
$40 \%$ of patients. In another study by Salim Yusuf et al ${ }^{4}$ study, $65.19 \%$ of patients were smokers. In our study, $50 \%$ of patients had dyslipidaemias. Most common lipid abnormalities were high triglycerides and low HDL levels. In Foussas et al ${ }^{1}$ study, $64.6 \%$ of patients had lipid abnormalities and in Mohmoud Suleiman et al ${ }^{2}$ study $41 \%$ of patients had dyslipidaemias, thus suggesting dyslipidaemia as a major risk factor irrespective of race, sex and socioeconomic status. In our study, $22 \%$ of patients had diabetes as the risk factor. In Foussas et $\mathrm{al}^{1}$ study diabetes mellitus was seen in $31 \%$ of patients and Mohmoud Suleiman et $\mathrm{al}^{2}$ study diabetes was present in $30 \%$ of patients. Since diabetes is considered as a coronary heart disease equivalent, added presence of the same multiplies the mortality risk. In our study, 32\% patients had hypertension. But hypertension was seen more frequently in Foussas et al ${ }^{1}$ study (51\%) and Mohmoud Suleiman et $\mathrm{al}^{2}$ study (53\%). In "INTER HEART" study by Prof. Salim Yusuf et $\mathrm{al}^{4}$ hypertension was seen in only $19.3 \%$ of patients, if only South Asian population cohort was considered.

In our study, $78 \%$ of patients had ST segment elevation myocardial infarction. Almost similar number of patients had ST segment elevation myocardial infarction in Mohmoud Suleiman et al ${ }^{1}$ study.

In this study, $89 \%$ of patients with STEMI underwent reperfusion therapy in the form of pharmacological thrombolysis with streptokinase. About 32\% of patients underwent thrombolysis in Mohmoud Suleiman et al ${ }^{1}$ study.

In our study, $62 \%$ patients had increased ESR. Similar rise was described by Hersberg et al. ${ }^{5}$ In this study, raised total counts were seen in $24 \%$ of patients.

Thomson et al ${ }^{6}$ found similar rise in 1995.

In this study $44(44 \%)$ patients had raised levels $(\geq 0.6 \mathrm{mg} / \mathrm{dL}$ ) and $34(77 \%)$ patients who had raised levels met with complications.

Foussas et al $^{1}$ studied 1,846 patients with acute coronary syndromes and showed that elevated plasma CRP levels confer a significantly increased risk of future fatal or nonfatal ischaemic complications.

The study by Mohmoud Suleiman et $\mathrm{al}^{2}$ concluded that plasma CRP levels obtained within 12 - 24 hours of symptom onset is an independent marker of 30-day mortality and the development of heart failure in patients with acute myocardial infarction.

S Bhagat et $\mathrm{al}^{7}$ compared 44 unstable angina patients with 40 age and sex matched healthy controls. They concluded that the plasma CRP is an independent predictor of adverse cardiac outcomes in severe unstable angina, in short-term follow-up and hence is useful for risk stratification of these patients. Pietila $\mathrm{K}^{8}{ }^{8}$ showed that high serum CRP concentrations in acute myocardial infarction patients treated with thrombolytic drugs predict increased mortality up to 6 months following the myocardial infarction.

Haruo Tomada et $\mathrm{al}^{9}$ studied a total of 234 patients with acute myocardial infarction and concluded that CRP levels within 6 hours after the onset of symptoms reflect the vulnerability of culprit coronary lesions and predict adverse coronary events after primary PTCA/stenting. P Mishra et $\mathrm{al}^{3}$ studied 50 cases of acute myocardial infarction and observed that serum CRP concentration on admission is a significant prognostic indicator of theirs in hospital stay. 
Comparing with these studies, in our study also increased levels of plasma C-Reactive Protein was associated with more adverse events.

\section{CONCLUSION}

Our study findings highlights a possible correlation between CRP levels and adverse outcomes in acute coronary syndrome. Plasma CRP levels on admission serves to identify high risk patients in the setting of acute coronary syndromes. The effective risk stratification provided may be of specific value for early therapeutic decision making and patient treatment in the heterogeneous population of patients presenting with acute coronary syndromes.

Raised CRP levels are independent markers of adverse outcomes. These findings suggest that in patients with acute coronary syndromes, CRP levels may be related to inflammatory processes associated with multiple plaque rupture or infarct expansion, thus making it imperative for an aggressive search for the same.

\section{REFERENCES}

[1] Foussas SG, Zairis MN, Lyras AG, et al. Early prognostic usefulness of $\mathrm{C}$-reactive protein added to thrombolysis in myocardial infarction risk score in acute coronary syndromes. Am J Cardiol 2005;96(4):533-7.

[2] Suleiman M, Aronson D, Reisner SA, et al. Admission Creactive protein levels and 30-day mortality in patients with acute myocardial infarction. Am J Med 2003;115(9):695-701.
[3] Huggins GS, O'Gara PT. Clinical presentation and diagnostic evaluation of atherosclerosis and coronary artery disease. Philadelphia: Lippincott-Raven 1996.

[4] Yusuf S, Hawken S, Ounpuu S, et al. Effect of potentially modifiable risk factors associated with myocardial infarction in 52 countries (the INTERHEART study). Am Heart J 1963;65:749-57.

[5] Hershberg PI, Wells RE, McGandy RB. Hematocrit and prognosis in patients with acute myocardial infarction. JAMA 1972;219(7):855-60.

[6] Thomson SP, Gibbons RJ, Smars PA, et al. Incremental value of the leucocyte differential and rapid creatine kinase MB isoenzymes for the early diagnosis of myocardial infarction. Annals of Internal Medicine 1995;122(5):335-41.

[7] Bhagat S, Gaiha M, Sharma VK, et al. A comparative evaluation of C-reactve protein as a short term prognostic marker in sever unstable angina-a preliminary study. JAPI 2003;51:349-54.

[8] Pietila KO, Harmonen AP, Jokinitty J, et al. Serum C reactive protein concentration in acute myocardial infarction and its relationship to mortality during 24 months of follow-up in patients under thrombolytic treatment. Eur Heart J 1996;17(9):1345-9.

[9] Tomada $\mathrm{H}$, Aoki N. Prognostic value of $\mathrm{C}$ reactive protein levels within six hours after the onset of acute myocardial infarction. Am Heart J 2000;140(2);324-8. 